\title{
Cytomegalovirus enteritis in a mechanically ventilated patient with chronic obstructive pulmonary disease
}

\author{
F. Y. Khan, N. A. Morad*
}

Massive lower gastrointestinal (GI) hemorrhage is a rare manifestation of Gl cytomegalovirus (CMV) infection,
in a critically ill patient. We report a 69 -year-old man, known to have chronic obstructive pulmonary disease
on ventilator, who developed sudden onset abdominal pain and massive lower Gl bleeding. Due to
uncontrolled bleeding, the patient was explored surgically. Bleeding from ileum was evident. The affected
segment of the ileum was resected. Histology confirmed the diagnosis of CMV enteritis and Gancyclovir
was initiated. On the following days, his physical state had improved and bleeding was resolved.
Key words: Cytomegalovirus, lower Gl bleeding, enteritis.

Cytomegalovirus (CMV) diseases occur almost exclusively in the immunocompromised hosts. Persons most commonly affected are patients with acquired immunodeficiency syndrome (AIDS). On rare occasions, however, CMV diseases can be seen in apparently immunocompetent persons.

\section{Case Report}

A 69-year-old man with a history of severe chronic obstructive pulmonary disease on home oxygen, was admitted with a 3-day history of worsening dyspnea and productive cough, with purulent sputum. He underwent multiple admissions to the medical intensive care unit (ICU), due to respiratory failure. Initial evaluation revealed an elderly man in moderate to severe respiratory distress, not able to speak in full sentences, with a BP 130/90 $\mathrm{mmHg}$, Pulse of 110 beats/min; Lungs had decreased

\section{From:}

Departments of Medicine and *Pathology, Hamad General Hospital,

Doha-Qatar

\section{Correspondence:}

Fahmi Yousef Khan, Department of Medicine, Hamad General Hospital, DohaQatar. E-mail: fakhanqal@yahoo.co.uk breath sounds, with occasional expiratory wheezing. Initial arterial blood gas analysis was as follows: $\mathrm{PH}, 7.25$; $\mathrm{PaCO} 2,70$; and $\mathrm{PaO} 2$ 48. Chest radiograph showed hyperinflation, without infiltrates or pneumothorax. Neublized Bronchodilators, intravenous antibiotics and steroids were initiated. After one hour, on follow up, he became more dyspnic and the arterial blood gas showed a pH of $7.00, \mathrm{PaCO} 2$ of 100 and $\mathrm{PaO} 2$ of 55 . The patient was intubated and ventilated with assist control and volume control, for hypercapnic respiratory failure. Neublized Bronchodilators, intravenous antibiotics and steroids were continued. On the following days, the patient become stable and steroids were tapered, until stopped. Weaning failed on several attempts, due to many factors: first, advanced lung disease, second, generalized muscular weakness. Third, recurrent chest infection.

On the $15^{\text {th }}$ hospital day, the patient developed severe abdominal pain and massive lower gastrointestinal bleeding. Initial examination was notable for a temperature of $37.7^{\circ} \mathrm{C}$, pulse of 113 beats $/ \mathrm{min}$, respiratory rate of $21 / \mathrm{min}$ and blood pressure of $100 / 60$ $\mathrm{mm} \mathrm{Hg}$. He appeared ill and the examination of the 
abdomen revealed tenderness on the periumblical area without organomegaly. Rectal examination was positive for bright red blood.

Initial investigations revealed a hemoglobin concentration of $8 \mathrm{gm} / \mathrm{dL}, \mathrm{WBC} 4500 / \mathrm{uL}$ and platelet count of $200,000 /$ LL. Blood chemistry, liver profile and coagulations studies, were within normal limits, as well as serum lipase and amylase. Hepatitis $C$ antibody, hepatitis B markers and antibody to the human deficiency virus, were negative. Bacterial cultures of the stool were negative.

Tagged red blood cell studies, endoscopy and angiogram failed to demonstrate any active eding site. Bleeding continued and despite the transfusion of several units of blood, the hemoglobin did not go up. During exploratory laporotomy, ilieal ulceration and bleeding were evident; the affected segment of the ileum was resected. Microscopically, resected terminal ileum revealed superficial mucosal ulcer with non specific chronic inflammatory infiltrate [Figure 1], beneath the ulcer group of enlarged endothelial cells with large nuclei and prominent intranuclear amphophilic viral inclusions were found [Figure 2]. Immunohistochemical stain using cytomegalovirus antibody revealed brown staining of the nucleus of a CMV infected endothelial cell [Figure 3].

IgG antibody titer to CMV was low, but IgM titer was high and Gancyclovir was initiated. On the following days, his physical state had improved and bleeding was resolved.

\section{Discussion}

CMV is a member of the Herpesviridae family, which includes the Epstein-Barr virus (EBV), herpes simplex virus, varicella-zoster virus and herpesvirus 6,7 and 8 .

CMV infection is worldwide and usually asymptomatic. Like other members of the Herpesvirus family, CMV establishes latent infection in the tissues of the human host after the resolution of acute infection, reactivating and shedding, when the host's immune system is compromised. The proportion of humans with evidence of prior CMV infection varies throughout the world, with seroprevalence rates ranging between 40 to 100 percent of the adult population. ${ }^{[1]}$ Seroprevalence generally correlates inversely with a country's socioeconomic

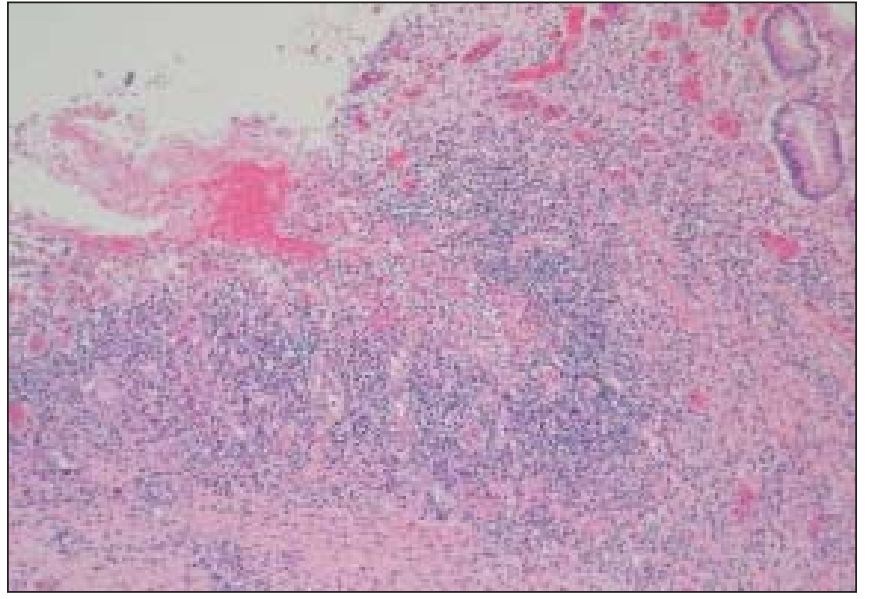

Figure 1: A low power view of histopathology section showing a superficial mucosal ulcer with non-specific chronic inflammatory infiltrate $(H / E, 65 x)$.

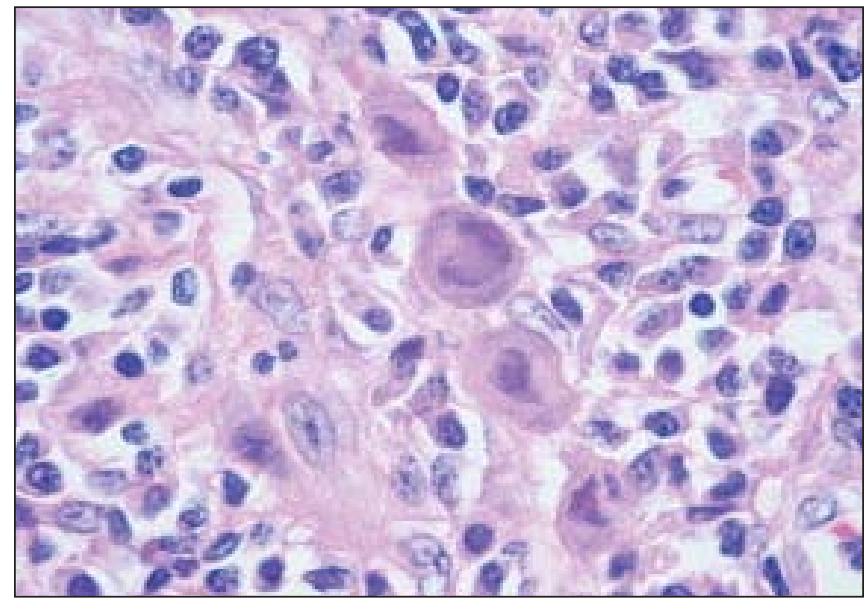

Figure 2: A high power view of the inflammatory ulcer base showing group of enlarged endothelial cells with large nuclei and prominent intranuclear amphophilic viral inclusions (H/E, 280x).

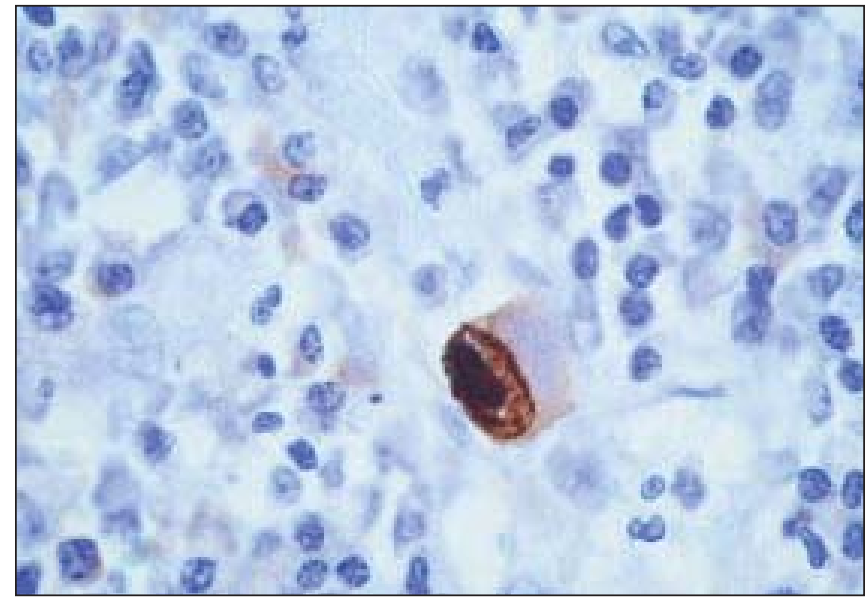

Figure 3: Immunohistochemical stain using cytomegalovirus antibody showing brown staining of the nucleus of a CMV infected endothelial cell (Immunohistochemical stain; original magnification 280x). 
development, with highest rates observed in developing countries throughout Africa and Asia. ${ }^{[2]}$

Secondary, symptomatic disease may present later in the life of the host, reflecting one of two possibilities: reactivation of latent $\mathrm{CMV}$, or reinfection with a novel exogenous strain.

CMV is not highly contagious. It is contracted from close personal contact with people who excrete the virus in their body fluids (e.g, saliva, urine, blood, breast milk, semen and even transplanted organ tissue). It also can be shed from the throat and uterine cervix. ${ }^{[3]}$

Transmission can occur via multiple routes: during perinatal period or sexual intercourse,,$^{[4]}$ close contacts, ${ }^{[5,6]}$ blood or tissue exposure ${ }^{[7]}$ and occupational..6]

In our patient, there was no obvious source of infection and most probably the patient developed secondary disease due to reactivation of latent CMV.

Cytomegalovirus (CMV) is an important human pathogen, causing a variety of syndromes ranging from asymptomatic infections to life-threatening end-organ disease. ${ }^{[8]}$ The most common site of involvement by CMV infection in the GI tract, is the colon followed by the upper GI tract and the least common site is the small intestine. ${ }^{[9]}$ Cytomegalovirus infections of the alimentary tract have been reported mainly in severely immunocompromised patients, or those with predisposing disorders such as ulcerative colitis. ${ }^{[10]}$ Another risk factor includes, the critically ill patient. ${ }^{[11]}$ Although Gl bleeding is one of the major presenting symptoms of patients with CMV infections of the GI tract, ${ }^{[9]}$ massive lower gastrointestinal bleeding related to CMV ulceration in small bowel, is rare. ${ }^{[12]}$ Our patient was not receiving steroids or any immunosuppressive drugs, but he was debilitated and critically ill.

The use of serology and parallel PCR analysis to confirm the diagnosis of cytomegalovirus infection, should enable early antiviral therapy to be instituted, resulting in marked clinical improvement.

Histology, demonstrating the classical appearance of "owl's eye" inclusion bodies, is the gold standard test for cytomegalovirus diagnosis. However, recent studies using PCR have indicated that it may be a sensitive and specific assay for diagnosis. ${ }^{[13,14]}$

If CMV infection is confirmed, Ganciclovir therapy should be initiated without delay. Immediate surgical resection and prompt antiviral therapy, lead to successful treatment. Our patient had improved and bleeding was stopped, when Gancyclovir was initiated after resection of the ileum. Mortality rates for patients with cytomegalovirus enterocolitis have been quoted as high as $71 \%{ }^{[15]}$

In conclusion, physicians must be aware of CMV enterocolitis and Immediate surgical resection and prompt antiviral therapy as the main treatment. Therefore, CMV enterocolitis should be considered in the differential diagnosis of lower gastrointestinal bleeding, in any debilitated and/or mechanically ventilated patient.

\section{References}

1. Krech U. Complement-fixation antibodies against cytomegalovirus in different parts of the world. Bull World Health Organ 1973;49:03.

2. Ho M. Epidemiology of cytomegalovirus infections. Rev Infect Dis 1990;12:S701.

3. Taylor H. Cytomegalovirus. Am Fam Physic 2003:67:519-24.

4. Jordan MC, Rousseau WE, Noble GR, Steward JA, Chin TD. Association of cervical cytomegaloviruses with venereal disease. N Engl J Med 1973;288:932-4.

5. Pass RF, Little EA, Stagno S, Britt WJ, Alford CA. Young children as a probable source of maternal and congenital cytomegalovirus infection. N Engl J Med 1987;316:1366-70.

6. Adler S. Molecular epidemiology of cytomegalovirus: Viral transmission among children attending a day care center, their parents and caretakers. J Pediatr 1988;112:366.

7. Tolpin MD, Steward JA, Warren D, Mojica BA, Collins MA, Doveikis SA, et al. Transfusion transmission of cytomegalovirus confirmed by restriction endonuclease analysis. J Pediatr 1985;107:953-6

8. Bobak DA. Gastrointestinal Infections Caused by Cytomegalovirus. Curr Infect Dis Rep 2003;5:101-7.

9. Cheung $\mathrm{AN}, \mathrm{Ng} I \mathrm{Q}$. Cytomegalovirus infection of the gastrointestinal tract in non-AIDS patients. Am J Gastroenterol 1993;88:1882-6

10. Taniwaki S, Kataoka M, Tanaka H, Mizuno Y, Hirose M. Multiple ulcers of the ileum due to Cytomegalovirus infection in a patient who showed no evidence of an immunocompromised state. J Gastroenterol 1997;32:548-52. 
11. Chamberlain RS, Atkins S, Saini N, White JC. Ileal perforation caused by cytomegalovirus infection in a critically ill adult. J Clin Gastroenterol 2000;30:432-5.

12. Lai IR, Chen KM, Shun CT, Chen MY. Cytomegalovirus enteritis causing massive bleeding in a patient with AIDS. Hepatogastroenterology 1996;43:987-91.

13. Brytting M, Xu W, Wahren B, Sundqvist VA. Cytomegalovirus DNA detection in sera from patients with active cytomegalovirus infection. J Clin Microbiol 1992;30:1937-41.
14. Schmidt CA, Oettle H, Peng R, Neuhaus P, Blumhardt G, Lohmann $\mathrm{R}$, et al. Comparison of polymerase chain reaction from plasma and buffy coat antigen detection and occurrence of immunoglobulin $\mathrm{M}$ for the demonstration of cytomegalovirus infection after liver transplantation. Transplantation 1995;59:1133-8.

15. Kaufman HS, Kahn AC, lacobuzio-Donahue C, Talamini MA, Lillemoe KD, Hamilton SR. Cytomegalovirus enterocolitis: Clinical associations and outcome. Dis Colon Rectum 1999;42:24-30. 